Case report

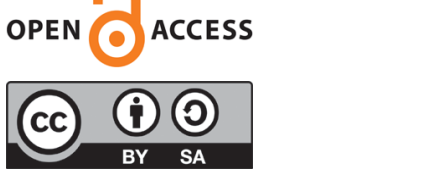

\title{
LOWER LIP CANCER - A CASE REPORT
}

\author{
Rosen Tsolov ${ }^{1}$, Georgi Yordanov ${ }^{2}$, Silvia Tsvetkova-Trichkova ${ }^{3}$, Iliya Peev ${ }^{4}$, \\ 1) Department of Maxillo-facial and Oral surgery, Saint George Hospital Uni- \\ versity Medical Center, Plovdiv, Bulgaria. \\ 2) Department of Allergology, Physiotherapy and Clinical radiology, Faculty \\ of Dental Medicine, Saint George Hospital University Medical Center, Plovdiv, \\ Bulgaria. \\ 3) Department of Imaging Diagnostics, Medical University, Plovdiv, Bulgaria. \\ 4) Clinics of Maxillofacial Surgery, Saint Marina Hospital University Medi- \\ cal Center, Varna, Bulgaria.
}

\begin{abstract}
A case report of a patient with cancer of the lower lip is presented. The reason for the treatment is an entity in the lower lip. It has been dating for several months and has grown significantly lately. Due to the complicated, inflammatory process, he was treated in the clinic, and after the same subsidence, he was admitted for surgical treatment. Surgery performed Resectio Partialis Labii Inferioris and plastics "a modo Bernard". The case was presented to an oncology council, establishing that the patient was being monitored and he was given recommendations for a hygienic diet. The patient was discharged with improvement.
\end{abstract}

Keywords: lower lip cancer, a case report

\section{INTRODUCTION}

1. Epidemiology

1.1. Tendency

Increased incidence of OCC (Oral Cavity Cancer) was founded in Europe in recent years. The frequency in the UK is up to $3 \%$, which would be explained by the higher alcohol consumption [1]. The same was reported for African Americans in USA for the period of 1974-1990. In Japan, there was also an increasing incidence of 2.7 / 100000 in 1975 . to 5.4 in 1995 , which remained stable as of 2001. In France, on the contrary, the incidence of OCC in men decreased for the period 1980-2000 [1].

\subsection{Mortality}

According to the literature review, the OCC mortality rate has increased over the period 1950-1980 in most European countries [169,265]. A significant increase in mortality was observed in men from countries in Eastern Europe (Bulgaria, Czech Republic, Hungary, Poland, Romania and Slovakia) [1]. Extremely high levels were observed for Hungary in the mid-1990s, where the mortality rate was 20.2 per 100,000 . Young patients in Western Europe have a weak but persistent upward trend in mortality $[1,2]$.

\subsection{Survival rates}

According to the data of leading Bulgarian oncologists, the survival rate from OCC did not increase, and half of the patients died in the first two years [1, 2, 3, 4]. OCC mortality is high and, despite advances in cancer treatment, no significant improvement was observed $[1,5]$.

\section{QUALITY OF LIFE}

Severe esthetic and functional disorders in eating, swallowing, drinking, speaking are observed in patients with OCC [6]. Although these residuals can lead to depression or malnutrition, many patients are coping. Quality of life is extremely important for this group of patients. A very significant problem is social rehabilitation to prevent the isolation of the patient into society $[7,8$, 9]. Very low survival rates have been reported in developing countries, mainly due to late diagnosis. The main cause of death is local recurrence [10].

\section{CASE REPORT}

In addition to surgical treatment, some of the tasks set include identifying risk factors, social etiology and improving hygiene habits to prevent recurrence and to improve quality of life [9, 10, 11].

Facial asymmetry is observed due to an exophytic formation centrally located on the lower lip with $3 \times 2 \mathrm{~cm}$ measurement and several small satellite tumors near the main formation. There is no evidence of lymphadenomegaly in the maxillofacial region.

Computed tomography showed a formation in the lower lip. Subthreshold lymph nodes up to $6 \mathrm{~mm}$ in size and submandibular bilateral up to $9 \mathrm{~mm}$ were visualized. The presence of pronounced degenerative changes in C5 such as the vertebral body is wedge-shaped. ICD code 27.49 Other excision of the mouth. 
Fig. 1. Cancer before treatment.

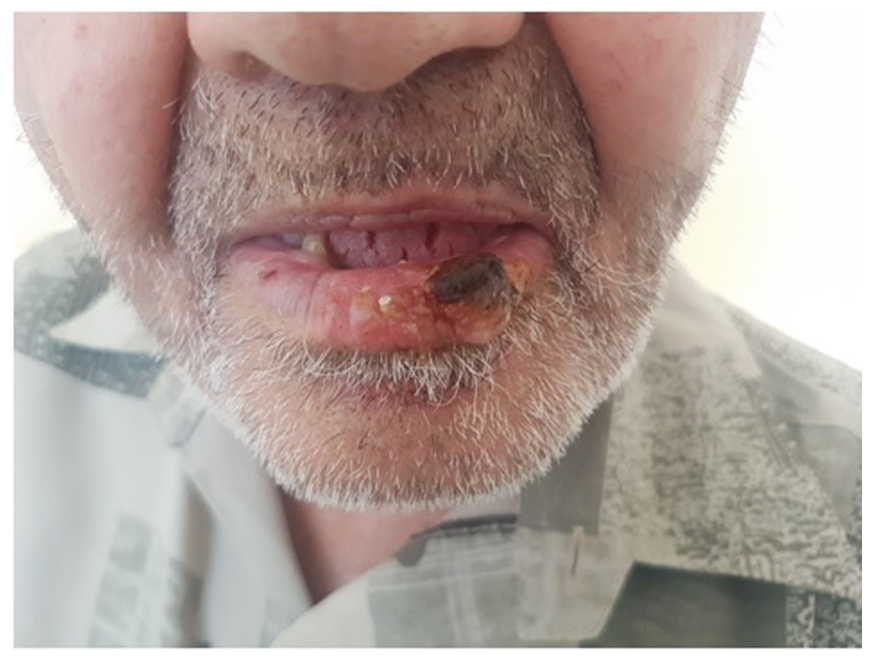

Fig. 2. After excision of the cancer

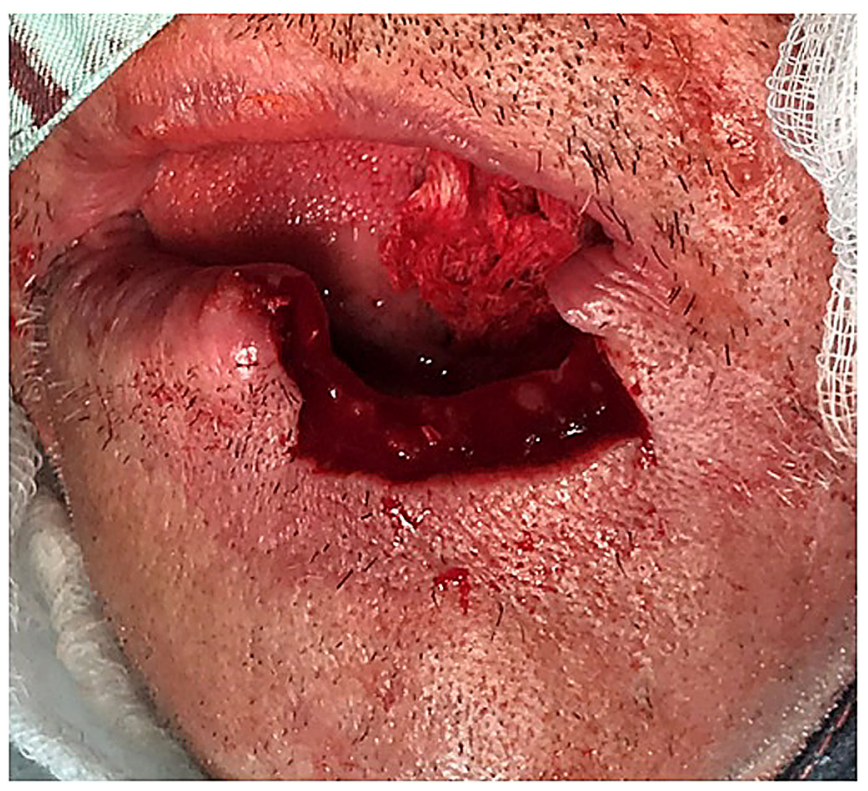

Fig. 3. Formation removal/specimen/.

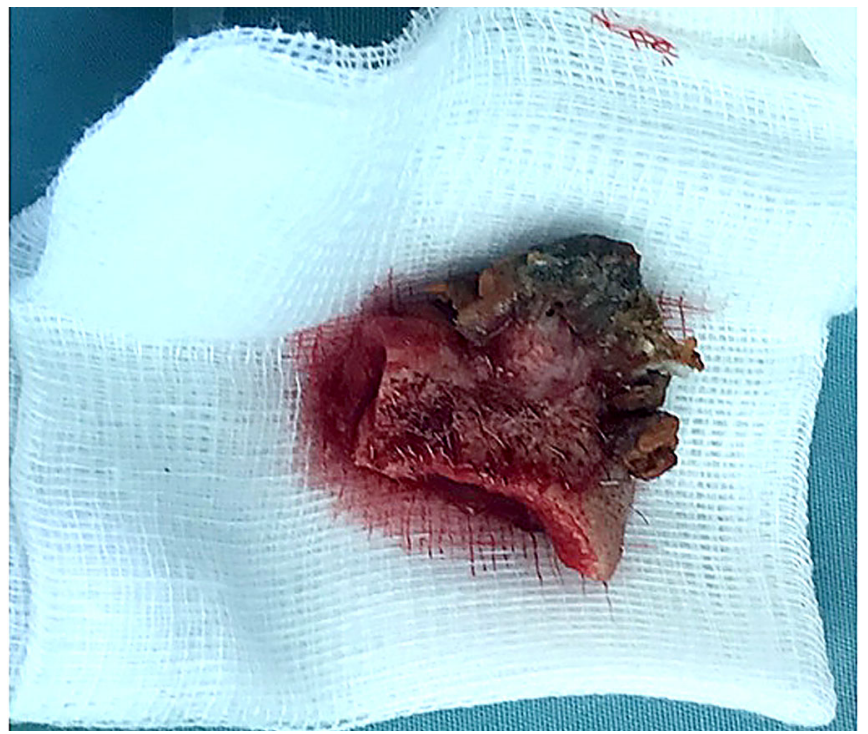

Fig. 4. Plastics of the lower lip.

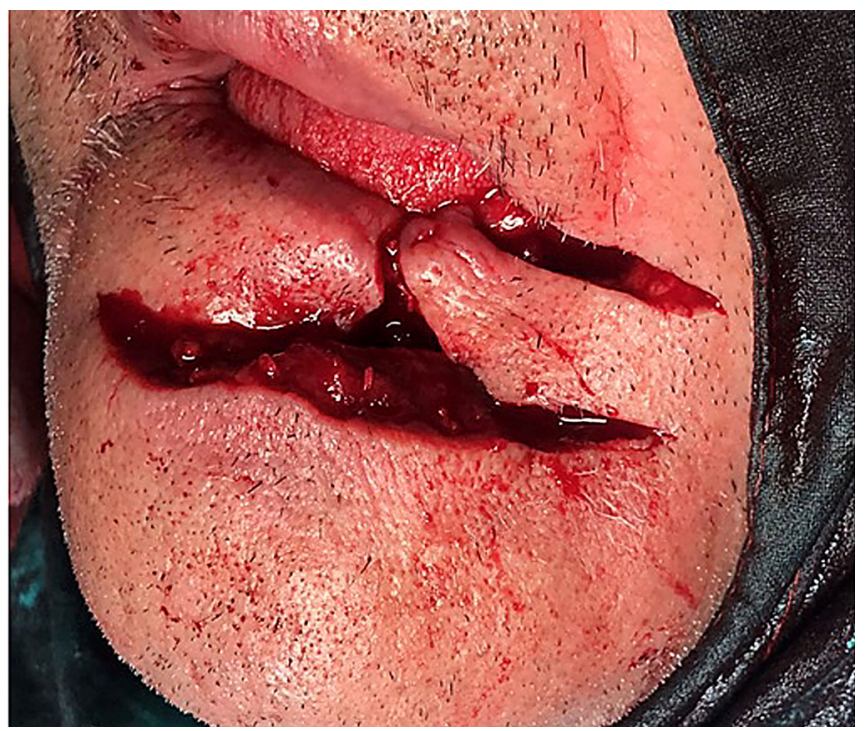

Fig. 5. After suturing during the intervention

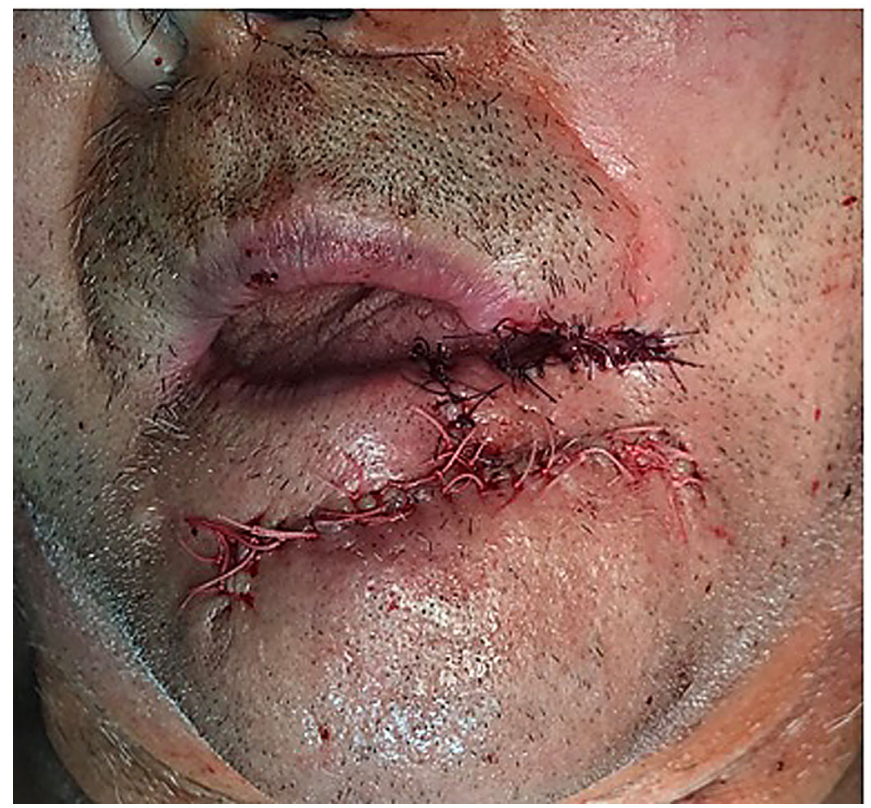

Fig. 6. The operative field 3 days after excision

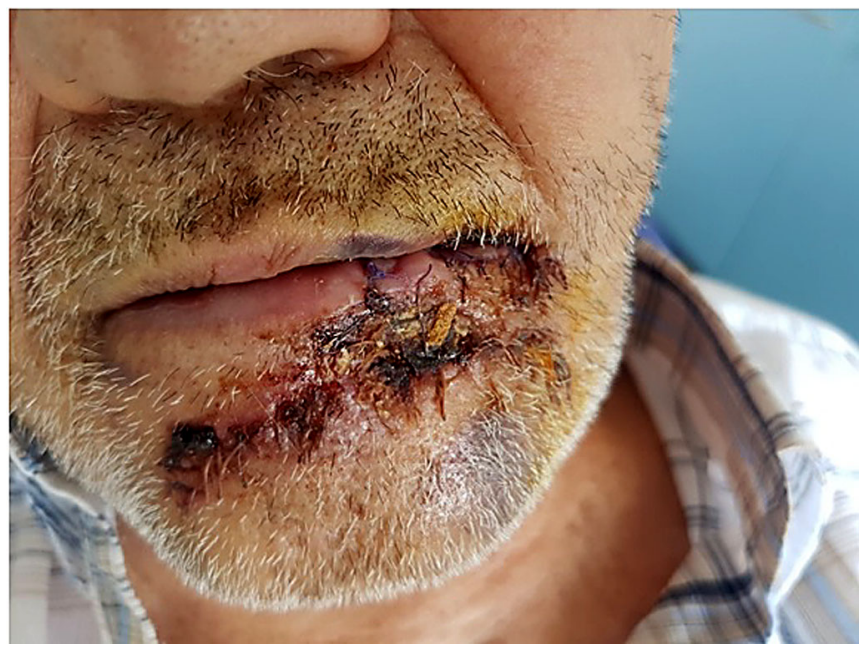


Therapy: Cefotaxime 1,0 2x1; Fraxiparine 0,4 1x1; Tramalgin $2 \times 1$. The scheduled treatment was for 7 days.

\section{DISCUSSION}

The case was discussed by an oncology council, whose final conclusion was that the surgical treatment has led to a general improvement of patient's quality of life, and he should be a subject to dispensary monitoring. Two controls were appointed within one month - on the 7th and 14th days. Recommendations are given to the patient for the hygiene and nutrition regimen, and to the dentist for the repairmen and sanitation of the oral cavity $[10,11,12]$.

\section{CONCLUSION}

The optimal treatment of the patient with ICD 27.49 Other excision of the mouth includes tumor excision, lymph node dissection and reconstruction with plastics "a modo Bernard". Recovering of the big lower lip's defect was conducted. This case presents a serious challenge from a surgical point of view to guarantee safety and adequate cosmetic and functional improvement of patients with OCC.

\section{REFERENCES:}

1. Stanimirov P. [Prognostic factors in squamous cell carcinoma of the oral cavity] [dissertation]. Medical University, Sofia, Bulgaria. 2013. 211p. [in Bulgarian].

2. Bettendorf O, Piffko J, Bankfalvi A. Prognostic and predictive factors in oral squamous cell cancer: important tools for planning individual therapy? Oral Oncol. 2004 Feb;40(2):110-9. [PubMed]

3. Bryne M, Nielsen K, Koppang HS, Dabelsteen E. Reproducibility of two malignancy grading systems with reportedly prognostic value for oral cancer patients. J Oral Pathol Med. 1991 Sep;20(8):369-72. [PubMed]

4. Siegelmann-Danieli N, Hanlon A, Ridge JA, Padmore R, Fein DA, Langer CJ. Oral tongue cancer in patients less than 45 years old: institutional experience and comparison with older pa- tients. J Clin Oncol. 1998 Feb;16(2): 745-53. [PubMed]

5. Ugrinov R. [Maxillofacial and Oral Surgery.] Sofia. 2006. [in Bulgarian]

6. British Dental Association. BDA occasional paper No. 6. Opportunistic oral cancer screening; April 2000.

7. Peeva Yu. A clinical protocol for orthodontic treatment of a patient with Turner syndrome. Fourth Eastern European conference for rare diseases and orphan drugs "Together for integrating approach to rare diseases", 2009, pp 156.

8. Peeva Yu. An Orthodontic Considerations and Surgical Approach for Three Impacted Canines-A Case Report. EC Dental Science. 2017; 11(2): 77-81. [Internet]

9. Peeva YB. Oral Health Prevention and the Current Healthcare System in
Bulgaria. EC Dental Science. 2019; 18(3):372-376. [Internet]

10. Woolgar JA, Rogers S, West CR, Errington RD, Brown JS, Vaughan ED. Survival and patterns of recurrence in 200 oral cancer patients treated by radical surgery and neck dissection. Oral Oncol. 1999 May;35(3):257-65. [PubMed]

11. Peeva YB. Personal Recommendations and Tips to Orthodontic Patients: A Systematic Review. J Oral Med. 2017; 1(1):8. [Internet]

12. Daskalova E, Delchev S, Peeva Y, Vladimirova-Kitova L, Kratchanova M, Kratchanov C, et al. Antiatherogenic and Cardioprotective Effects of Black Chokeberry (Aronia Melanocarpa) Juice in Aging Rats. Evid Based Complement Alternat Med. 2015; 2015:717439. [PubMed] [Crossref].

Please cite this article as: Tsolov R, Yordanov G, Tsvetkova-Trichkova S, Peev I. Lower lip cancer - a case report. J of IMAB. 2020 Oct-Dec;26(4):3345-3347. DOI: https://doi.org/10.5272/jimab.2020264.3345

Address for correspondence:

Rosen Tsolov, Department of Maxillo-facial and Oral surgery, Saint George Hospital University Medical Center, 66 , Peshtersko Shose blvd., Plovdiv, Bulgaria

E-mail: dr.rosentsolov@gmail.com, 